\title{
Leukocyte Esterase Measurement
}

National Cancer Institute

\section{Source}

National Cancer Institute. Leukocyte Esterase Measurement. NCI Thesaurus. Code C64856.

A quantitative measurement of the amount of leukocyte esterase present in a sample. 